\title{
Does pharmaceutical advertising affect journal publication about dietary supplements?
}

\author{
Kathi J Kemper*1 and Kaylene L Hood ${ }^{2}$
}

Address: ${ }^{1}$ Department of Pediatrics and the Program for Complementary and Integrative Medicine, Wake Forest University School of Medicine, Winston-Salem, NC, USA and ${ }^{2}$ University of Florida, Department of Nutrition, Gainesville, FL, USA

Email: Kathi J Kemper* - kkemper@wfubmc.edu; Kaylene L Hood - Kayhood@ufl.edu

* Corresponding author

Published: 9 April 2008

BMC Complementary and Alternative Medicine 2008, 8: I I doi:I0.1 I86/|472-6882-8-I I

This article is available from: http://www.biomedcentral.com/I472-6882/8/I I

(c) 2008 Kemper and Hood; licensee BioMed Central Ltd.

This is an Open Access article distributed under the terms of the Creative Commons Attribution License (http://creativecommons.org/licenses/by/2.0), which permits unrestricted use, distribution, and reproduction in any medium, provided the original work is properly cited.
Received: 6 August 2007

Accepted: 9 April 2008

\begin{abstract}
Background: Advertising affects consumer and prescriber behaviors. The relationship between pharmaceutical advertising and journals' publication of articles regarding dietary supplements (DS) is unknown.
\end{abstract}

Methods: We reviewed one year of the issues of II major medical journals for advertising and content about DS. Advertising was categorized as pharmaceutical versus other. Articles about DS were included if they discussed vitamins, minerals, herbs or similar products. Articles were classified as major (e.g., clinical trials, cohort studies, editorials and reviews) or other (e.g., case reports, letters, news, and others). Articles' conclusions regarding safety and effectiveness were coded as negative (unsafe or ineffective) or other (safe, effective, unstated, unclear or mixed).

Results: Journals' total pages per issue ranged from 56 to 217 while advertising pages ranged from 4 to 88; pharmaceutical advertisements (pharmads) accounted for $1.5 \%$ to $76 \%$ of ad pages. Journals with the most pharmads published significantly fewer major articles about DS per issue than journals with the fewest pharmads $(P<0.0 \mathrm{I})$. Journals with the most pharmads published no clinical trials or cohort studies about DS. The percentage of major articles concluding that DS were unsafe was $4 \%$ in journals with fewest and $67 \%$ among those with the most pharmads $(P=0.02)$. The percentage of articles concluding that DS were ineffective was $50 \%$ higher among journals with more than among those with fewer pharmads $(P=0.4)$.

Conclusion: These data are consistent with the hypothesis that increased pharmaceutical advertising is associated with publishing fewer articles about DS and publishing more articles with conclusions that DS are unsafe. Additional research is needed to test alternative hypotheses for these findings in a larger sample of more diverse journals.

\section{Background}

Interest in vitamins, minerals, herbs and other dietary supplements (DS) has grown markedly in the US since the early 1990's [1-10]. DS are defined by the US Food and Drug Administration as "vitamins, minerals, herbs or other botanicals, amino acids, and substances such as enzymes, organ tissues, glandulars, and metabolites." DS are commonly used $[2,3,11,12]$. In certain cases, DS are medically recommended (e.g., folic acid for women of child-bearing age [13]). However, for most supplements 
there are few official recommendations, and patients often use DS without informing their physician $[2,14,15]$. Physicians have been urged to discuss with their patients the effectiveness and safety of DS, particularly when combining use of DS with prescription medications [16-21].

In response to citizen demand and the high prevalence of DS use, the US National Institutes of Health have funded research to evaluate the safety and effectiveness of DS [22]. An increasing number of research papers about DS have been published recently, and a number of journals specifically devoted to CAM research and education have appeared. However, most primary care clinicians subscribe to established and highly visible general medical journals; articles in these journals are frequently cited in professional practice guidelines and by the media to guide the general public. Many medical journals are supported in part by advertising revenues; however, we are unaware of research evaluating the relationship between pharmaceutical advertising and publication about natural health products, which may in some cases be viewed as competitive with pharmaceutical products.

In general, the aim of advertising is to increase demand for and purchase advertised products. Direct to consumer pharmaceutical advertising affects consumer behavior $[23,24]$; advertising in medical journals and other marketing aimed at clinicians affects clinician prescribing behavior $[25,26]$. Pharmaceutical funding of research also appears to influence authors' interpretation of results (conclusions) about the effectiveness of these products [27]. It is possible that advertising funds may influence journals and their paid staff [25]. The potential conflicts of interest between advertisers, editors and authors have resulted in the emergence of guidelines and rules about disclosure of potential conflicts of interest, particularly for authors writing about the effectiveness and safety of specific products [28-34].

Because of the importance of established medical journals in informing and influencing professional and public behavior, the question of unintended bias favoring advertisers in making editorial decisions is of great public health as well as business interest. The purpose of this pilot study was to begin to explore the relationship between pharmaceutical advertising and the publication of articles about DS. We expected that journals with more pharmaceutical advertising would publish fewer articles about DS because DS may at times be viewed as competitors to pharmaceutical products; furthermore, we expected that those with more pharmaceutical advertisements (pharmads) would publish more articles suggesting that DS were unsafe or ineffective than journals with fewer pharmads. As a secondary question, we assessed publications about DS in three journals devoted to com- plementary and alternative medicine (CAM); we expected CAM journals would have fewer pharmads and more DS articles; finally, we expected that fewer of the articles in CAM journals would be unfavorable about DS than articles in the general medical and primary care journals.

\section{Methods \\ Data Sources}

We selected 11 major medical journals published in English between June 30, 2006 and June 30, 2007. Journals were selected if they were devoted to general medicine (American Family Physician, British Medical Journal, Canadian Medical Association Journal, Journal of the American Medical Association, and the New England Journal of Medicine; internal medicine (Annals of Internal Medicine and Archives of Internal Medicine, or pediatrics (Pediatrics, Archives of Pediatrics and Adolescent Medicine, and Pediatric Research). For each journal, all issues available in the Coy C. Carpenter Library at Wake Forest University School of Medicine (WFUSM) for the study time period were reviewed. We used the American library version of these journals and did not compare different versions that may have been published for various groups of subscribers.

The WFUSM library did not subscribe to hard copies of any CAM journals. For the secondary question about CAM journals, we reviewed a convenience sample of three journals with issues published in the same time period as for the other journals to which the WFUSM Program for Holistic and Integrative Medicine at WFUSM had a subscription: Journal of Alternative and Complementary Therapies, Alternative Therapies in Health and Medicine, and Explore.

\section{Reviews}

All reviews were carried out between May 21 and July 17, 2007. Journals were reviewed by two pre-medical students using standard rating forms created for the study. Reviewers were trained; inter-rater agreement was confirmed through independent review of journals. Reviewers examined each page of every journal reviewed. Pages were selected for the study if they included a) any kind of advertising or b) any report regarding a DS.

Advertising included pharmaceutical (including prescription and over-the-counter medications and ads for drugeluting stents); classified; self-promoting (e.g., advertisements for the journal itself, its parent organization or an affiliated publication or meeting); for-profit products (e.g., foods, automotive, office equipment), non-profit (e.g., for schools, foundations, and associations such as the American Heart Association), and other (e.g. US military and other). For analytic purposes, these were collapsed into two categories: pharmaceutical versus other. 
Pages that contained advertising were counted as full, half (0.5) or quarter $(0.25)$ ad pages for each type of ad.

Reports about DS were included if they were found in original manuscripts, reviews, editorials, abstracts, news, meeting notes, patient information, or letters to the editor. These materials are referred to for purposes of this paper as journal "articles" about DS. Indices and tables of contents were not included in the review. DS were defined as per the US FDA definition cited above. We excluded articles about tobacco, marijuana, alcohol products and about prescription medications derived from plants. We did not include articles about specific diets such as high fiber, low fat, low glycemic index, Mediterranean, Atkins, or specific foods such as milk, but we did include tea and coffee because many of these articles focused on their caffeine or antioxidant content. For analytic purposes, articles about DS were divided into major articles (original research, editorials, reviews) and other (basic scientific mechanisms, case reports, letters, fillers, news, abstracts, meeting notes, and similar) types of articles. We divided articles this way because original articles, reviews, and editorials tend to be picked up by the media and cited in subsequent review articles; even though editorials and reviews do not often include new data, they often contribute to policy and guideline development.

For each article about DS, reviewers examined the authors' conclusions regarding safety and effectiveness. Conclusions about safety were coded as a) unsafe, b) safe, or c) unclear or mixed or d) not discussed. For example, a conclusion citing "no serious adverse effects" was coded as "safe"; a conclusion that excessive vitamin A caused liver disease would be coded as "unsafe"; some articles that focused solely on efficacy did not include a discussion of side effects. Similarly, conclusions about effectiveness were coded as a) ineffective, b) effective, or c) neutral, mixed or insufficient evidence or d) not discussed. Reviewers discussed cases in which there was initial disagreement about coding ( $<5 \%$ of cases); the two unresolved cases were referred to an attending physician for final decision about coding. Because we were particularly interested in negative publications, articles were categorized for analysis as "unsafe" versus "other" and as "ineffective" versus "other."

Data about each journal's impact factor was collected for 2006 on the journal websites.

Data were entered into a MS Access Database and transferred to MS EXCEL for descriptive analysis; Stata ${ }^{\mathrm{TM}} 8.1$ software was used for statistical analysis. Comparisons between groups of journals with the most, middle and fewest articles per issue were made with Fisher's exact test due to the small sizes of some cells.
As an analysis of published materials, this study was considered exempt from human subjects review.

\section{Results}

The number of issues reviewed for each of the 11 primary journals ranged from 12 to 52, with an average of 30 issues per journal (Table 1). The average number of pages per issue ranged from 56 to 217. The average number of all advertising pages (all-ads) ranged from 3.9 to 87.8 per issue. The average number of pharmaceutical ads (pharmads) varied from 0.15 to over 60 pages per issue and from 0.001 to 0.441 pharmads per average number of journal pages per issue. We arbitrarily grouped journals into those with less than ten pharmads in an average issue (the fewest pharmads group; two journals with an average impact factor 5.9); those with more than 40 pages of pharmaceutical ads per issue (the most pharmads group; two journals with an average impact factor 18.5), and those that had between 10-39 pages per issue (the middle ads group; seven journals with an average impact factor 6.9). Although we did not set out to review the number of pages devoted to DS advertising, reviewers noted that ads for DS such as Centrum ${ }^{\circledast}$ and Caltrate ${ }^{\circledast}$ were very rare among these 11 journals, and there were no ads for folate, individual vitamins or for non-vitamin/mineral DS such as glucosamine, ginkgo, or garlic in these 11 journals.

The number of articles of any type about any DS in each journal ranged from four to 61 (Table 2). The journals with the most pharmads published fewer major articles about DS per issue than journals with a middle number of ads $(0.08$ versus 0.21 per major articles per issue, $\mathrm{P}<$ $0.05)$; and journals with the middle number of pharmads published fewer major DS articles per issue than journals with the fewest pharmads $(0.21$ versus $0.43, \mathrm{P}<0.05)$, consistent with a dose-effect response. There was no apparent relationship between journals' impact factor and either their number of ads or their number of publications about DS. None of the 35 articles published about DS in the two journals with the most pharmads were clinical trials or observational cohort studies.

The DS that were covered the most often in these medical journals were (Table 3): folate and other B vitamins; calcium and vitamin D; iron; essential fatty acids such as omega three fatty acids; and caffeinated beverages such as coffee and green tea. There were fewer articles about probiotics, glucosamine, individual herbs (garlic, ginkgo, ginseng, St. Johns wort, lavender, tea tree oil) or combination herbal products.

Safety concerns were raised less often in clinical trials or cohort studies than in other articles. Specifically, concerns about unsafe DS were cited in $1 / 44(2 \%)$ clinical trials or cohort studies versus $3 / 34$ (10\%) of editorials or reviews, 
Table I: Journal advertising - Total pages and Pharmaceutical Ads (Pharmads)

\begin{tabular}{|c|c|c|c|c|c|c|}
\hline Journal & $\begin{array}{l}\text { No. of issues } \\
\text { reviewed }\end{array}$ & $\begin{array}{l}\text { Average No. of } \\
\text { Pages per issue }\end{array}$ & $\begin{array}{l}\text { Average No. of } \\
\text { All Ad pages } \\
\text { per issue }\end{array}$ & $\begin{array}{l}\text { Average No. } \\
\text { Pharmads } \\
\text { per issue }\end{array}$ & $\begin{array}{c}\text { Percent } \\
\text { Pharmad pages } \\
\text { per issue }\end{array}$ & $\begin{array}{c}\text { No. of } \\
\text { Pharmads } \\
\text { per Pages in } \\
\text { Avg. issue }\end{array}$ \\
\hline A & 24 & 182.9 & 87.8 & 66.3 & 75.5 & 0.362 \\
\hline B & 25 & 143.4 & 86.7 & 63.2 & 72.9 & $0.44 I$ \\
\hline $\mathrm{C}$ & 52 & 108.4 & 85.0 & 39.4 & 46.4 & 0.363 \\
\hline$D$ & 24 & 78.8 & 53.2 & 22.8 & 42.8 & 0.289 \\
\hline$E$ & 12 & 217.3 & 63.6 & 24.7 & 38.9 & 0.114 \\
\hline $\mathrm{F}$ & 12 & 109 & 21.7 & 15.7 & 72.3 & 0.144 \\
\hline G & 22 & 117.7 & 21.0 & 15.4 & 73.3 & 0.131 \\
\hline $\mathrm{H}$ & 50 & 86.1 & 22.2 & 15.2 & 67.5 & 0.177 \\
\hline 1 & 48 & 124.8 & 30.8 & 10.5 & 34.0 & 0.084 \\
\hline J & 52 & 56.1 & 3.9 & 0.15 & 3.9 & 0.003 \\
\hline $\mathrm{K}$ & 13 & 137.5 & 10.5 & 0.15 & 1.5 & 0.001 \\
\hline $\begin{array}{l}\text { OVERALL } \\
\text { AVERAGE for } \\
\text { major medical } \\
\text { journals }\end{array}$ & 30.4 & 123.8 & 43.04 & 23.5 & 48.1 & 0.192 \\
\hline CAM journals & & & & $\begin{array}{l}\text { Pharmads } \\
\text { (DS ads) p } \\
\text { er issue }\end{array}$ & $\begin{array}{l}\text { Percent } \\
\text { pharmads } \\
\text { (DS ads) }\end{array}$ & \\
\hline L & 6 & 79.2 & 8 & $0(1.8)$ & $0(23)$ & 0 \\
\hline$M$ & 7 & 103.7 & 5.7 & $0(0)$ & $0(0)$ & 0 \\
\hline $\mathrm{N}$ & 9 & 104.1 & 24 & $0(12.3)$ & $0(52)$ & 0 \\
\hline
\end{tabular}

Table 2: Articles about Dietary Supplements (DS)

\begin{tabular}{|c|c|c|c|c|c|c|}
\hline Characteristics & $\begin{array}{c}\text { Number of } \\
\text { issues reviewed }\end{array}$ & $\begin{array}{l}\text { Number of ANY } \\
\text { articles about DS }\end{array}$ & $\begin{array}{c}\text { Clinical Trials or } \\
\text { Cohort Studies }\end{array}$ & Editorials & Reviews & $\begin{array}{c}\text { TOTAL MAJOR } \\
\text { ARTICLES } \\
\text { (PER ISSUE)* }\end{array}$ \\
\hline $\begin{array}{l}\text { Most Pharmads ( } 2 \text { journals; } \\
\text { average impact factor } 6.9 \text { ) } \\
\text { TOTALS }\end{array}$ & 49 & 35 & 0 & 2 & 2 & 4 \\
\hline Number per issue & & 0.71 & 0 & 0.02 & 0.02 & $(0.08)^{*}$ \\
\hline $\begin{array}{l}\text { Middle Pharmads ( } 7 \text { journals; } \\
\text { average impact factor 18.5) } \\
\text { Totals }\end{array}$ & 220 & 142 & 30 & 15 & 2 & 47 \\
\hline Number per issue & & 0.65 & 0.14 & 0.07 & 0.01 & $(0.21)^{*}$ \\
\hline $\begin{array}{l}\text { Fewest Pharmads ( } 2 \text { journals; } \\
\text { average impact factor } 5.9 \text { ) } \\
\text { Totals }\end{array}$ & 65 & 77 & 14 & 11 & 3 & 28 \\
\hline Number per issue & & 1.2 & 0.22 & 0.17 & 0.05 & $(0.43)^{*}$ \\
\hline CAM JOURNALS & 22 & 88 & 11 & 2 & 6 & 19 \\
\hline Number per issue & & 4 & 0.5 & 0.09 & 0.27 & $(0.86) *$ \\
\hline
\end{tabular}

*Overall differences in rates of publishing major articles about DS are statistically significant with $\mathrm{P}<0.00 \mathrm{I}$. The rate for those with the most pharmads $(0.08)$ is significantly lower than those with middle pharmads $(0.21, P<0.05)$. The rate for those with the middle pharmads $(0.2 \mathrm{I})$ is significantly lower than those with the fewest pharmads $(0.43, P<0.05)$. The rate for the CAM journals $(0.86)$ is significantly higher than that for the general medical journals with the fewest pharmads $(<0.0 \mathrm{I})$ 
Table 3: Dietary Supplements Most Often Covered in Major Medical Journals

\begin{tabular}{lc}
\hline Supplement & Number of Articles \\
\hline Folate and other B vitamins & 37 \\
Coffee, green tea, caffeine & 20 \\
Calcium and/or Vitamin D & 18 \\
Iron & 11 \\
Omega-3 fatty acids & 9 \\
Multivitamins or multiple vitamin/nutrient mixtures & 6 \\
Lavender/tea tree & 6 \\
Vitamin A & 5 \\
Zinc & 5 \\
\hline
\end{tabular}

Other DS included probiotics, olive oil, antioxidants, garlic, Vitamins C, E, and K chondroitin, and black cohosh

and 20/177 (11\%) of other kinds of articles. Journals with the most pharmads were significantly more likely to publish major articles concluding that DS were unsafe than journals with middle or fewest pharmads (67\% versus $7 \%$ and $4 \%$, respectively, $\mathrm{P}<0.005$ Table 4 ).

In the 11 primary journals, 68/254 (26\%) articles about DS concluded they were ineffective; only 10 of these articles were clinical trials or cohort studies. Conclusions about ineffective DS were less common in journals with fewest pharmads than in journals with more pharmads. For example, half (50\%) of the editorials from journals with the most pharmads concluded that DS were ineffective, compared with 33\% of editorials from journals with middle amounts of pharmaceutical advertising and $27 \%$ of editorials from the journals with the least pharmaceuti- cal advertising (Table 4); these differences were not statistically significant.

For the secondary question about the three CAM journals, the number of advertisements ranged from 5.7 to 24 pages per issue (Table 1). There were no advertisements for prescription pharmaceuticals in any of the CAM journals. However, there were ads for DS; the number of pages of ads for DS ranged from 0 to 12.3 with an overall average of 5.5 ads for DS per issue. The CAM journals carried significantly more articles about DS than any group of the primary journals $(\mathrm{P}<0.01)$. The CAM journals published over twice as many clinical trials or cohort studies as the journals with the fewest pharmads $(0.5$ versus 0.22 per issue); the number of major articles per issue was significantly higher among CAM journals than among the general medical journals with the fewest ads $(0.86$ versus 0.43

Table 4: Articles concluding DS are Unsafe or Ineffective

\begin{tabular}{|c|c|c|c|c|c|}
\hline Characteristics & $\begin{array}{c}\text { N Unsafe/All DS arti- } \\
\text { cles (\%) }\end{array}$ & $\begin{array}{l}\text { Among Clinical or } \\
\text { Cohort Trials }\end{array}$ & Among Editorials & Among Reviews & $\begin{array}{l}\text { N Unsafe/TOTAL } \\
\text { MAJOR ARTICLES }\end{array}$ \\
\hline \multicolumn{6}{|l|}{ UNSAFE } \\
\hline Most Pharmads & $5 / 35(14)$ & $0 / 0(0)$ & $\mathrm{I} / \mathrm{I}(100)$ & $\mathrm{I} / 2(50)$ & $2 / 3(67)^{*}$ \\
\hline Middle Pharmads & $16 / 142(11)$ & $1 / 30(3)$ & $0 / 15(0)$ & $0 / 2(0)$ & $1 / 47(7)$ \\
\hline Fewest Pharmads & $3 / 77(4)$ & $0 / 14(0)$ & I/II (9) & $0 / 3(0)$ & $1 / 27(4)$ \\
\hline CAM Journals & $\mathrm{I} / 88(\mathrm{I})$ & 0 & 0 & 0 & $0 / 19(0)$ \\
\hline INEFFECTIVE & $\begin{array}{c}\mathbf{N} \text { Ineffective/All DS } \\
\text { articles (\%) }\end{array}$ & & & & $\begin{array}{c}\text { N Ineffective/TOTAL } \\
\text { MAJOR ARTICLES }\end{array}$ \\
\hline Most Pharmads & $12 / 35(34)$ & $0 / 0$ & $\mathrm{I} / 2(50)$ & $0 / 2(0)$ & I/4 (25) \\
\hline Middle Pharmads & $35 / 142(25)$ & $8 / 31(26)$ & $5 / 15(33)$ & $\mathrm{I} / 2(50)$ & $14 / 47(30)$ \\
\hline Fewest Pharmads & $21 / 77(27)$ & $2 / 14(14)$ & $3 / 1 I(27)$ & $0 / 3(0)$ & $5 / 27$ (19) \\
\hline CAM Journals & $11 / 88(13)$ & I/II (9) & $0 / 2(0)$ & I/6 (17) & $2 / 19$ (1I) \\
\hline
\end{tabular}

* General medical journals with the most pharmads published a significantly higher percentage of major articles concluding that DS were unsafe than the journals with middle or fewest pharmads or the CAM journals $(P<0.005)$.

The differences in rates of articles concluding that DS were ineffective among the different pharmad groups were not statistically significant. 
$\mathrm{P}<0.05)$. Although CAM journals published more original science about DS, the proportion of major articles concluding that DS were unsafe or ineffective was not significantly different from general journals with middle or fewest pharmads (Table 4).

\section{Discussion}

This is the first study to examine the relationship between advertising in medical journals and the publication of articles in those journals about DS. The results are consistent with the hypothesis that pharmaceutical advertising biases journals against non-drug therapies. Journals with the most pharmads per issue published significantly fewer major articles about DS than journals with fewer pharmads. For example, the two journals with the most pharmads published no clinical trials or cohort studies about DS. Furthermore, journals with the most pharmads were more likely to publish articles concluding that DS were unsafe than journals with fewer pharmads. CAM journals had no pharmaceutical ads, and they published significantly more original science articles about DS; however, they were not significantly less likely to publish major articles suggesting that DS were unsafe or ineffective than general medical journals with middle or few pharmads.

These results are generally consistent with a substantial body of research suggesting that advertising influences behavior. Advertising influences consumer behavior $[23,24]$. Advertising, particularly in the forms of gifts and samples, also influences physician prescribing behavior $[26,35,36]$. This study extends those findings, and it supports growing efforts to minimize potential conflicts of interest or at least make them more transparent, if eliminating them entirely is not feasible $[28,37,38]$.

It is possible that there might have been greater apparent impact on publication decisions if the analysis had been restricted to DS that are typically used to replace pharmaceutical products. The great majority of the articles about DS reviewed here were about caffeinated beverages and vitamins or other essential nutrients (minerals and essential fatty acids) which are not competitors of prescription medications. For the most part, recent research suggests that the DS most often used, including multivitamins, calcium, iron and folate, are those often recommended by professionals or those known to be deficient in the diet [39-41]. Furthermore, many vitamins are manufactured by pharmaceutical companies, thus reducing these companies' potential bias against DS. For example, Centrum ${ }^{\circledast}$ products and Caltrate ${ }^{\infty}$ are manufactured by Wyeth, the maker of Advil ${ }^{\oplus}$, Alavert ${ }^{\oplus}$, Effexor $^{\circledast}$ and Embrel $^{\circledR}$ among many other products. These facts would tend to favor the null hypothesis.
On the other hand, non-vitamin/mineral supplements, such as glucosamine, echinacea, garlic, ginseng, and ginkgo are also frequently used by the public, often concurrently with prescription medications $[12,20]$, yet the primary 11 journals included in the survey published few research studies, editorials or reviews on these DS. Future research will need to focus on publication about DS that may be viewed as greater threats to the pharmaceutical industry (such as non-vitamin/mineral products that are used by the public to promote weight loss, improve sexual or athletic performance, relieve joint or back pain, or to improve memory, cardiovascular health or GI health). Such research will need a large sample size of many types of journals; furthermore, such research will also need to account for potential confounding by research funding by DS manufacturers.

This pilot study has several limitations. It included only a few of the many clinical medical journals available and used only the American library version of these journals, but it did focus on those with very high readership that are often quoted by professional organizations, the media and policymakers. Results from the smaller secondary analysis of the CAM journals would be enhanced by larger sample of more diverse CAM publications. The review did not specifically address the funding for different trials or evaluate the methodologic quality of the published trials. This study was not a survey of journal editors regarding the number of submissions of different types they receive or how they decide which articles to include. An alternative hypothesis that might explain these findings is that journals with a high number of pharmaceutical ads receive few submissions about dietary supplements; furthermore, it is possible that a large number of articles about dietary supplements are of poor quality and do not deserve publication. It is also possible that the observed associations are due to another underlying factor ; for example, one recent study reported that in high impact journals, European journals were approximately twice as likely as American journals to publish positive articles about complementary therapies [42]. In addition, this study used the number of issues per journal as the study denominator rather than the total number of articles per issue; future studies could use the number of articles per issue as the denominator to address the related question of whether journals with more advertising per issue also have fewer articles of all types and hence fewer articles about dietary supplements. Future studies on this topic to explore alternative hypotheses for our findings should include a larger number of journals and more diverse journals; additional studies might also survey journal editors to determine the number of articles submitted for consideration for publication and ask about the percentage of submissions related to dietary supplements. 


\section{Conclusion}

These findings support the hypothesis that in major medical journals, more pharmaceutical advertising is associated with publishing fewer articles about DS and having more negative conclusions about DS safety. While awaiting future definitive studies to confirm these findings in a larger, more diverse sample of journals and to explore alternative explanations, these data support current efforts to reduce conflicts of interest in medical publishing and to make any such conflicts more transparent. The impact of advertising on publications appears to be non-trivial; the ultimate impact of this bias on professional guidelines, health care, and health policy is a matter of great public concern and underscores the need for additional health services research on this topic.

\section{Competing interests}

The author(s) declare that they have no competing interests.

\section{Authors' contributions}

KK conceived of the project, designed the data collection form, reviewed data analysis, drafted and revised the manuscript

$\mathrm{KH}$ reviewed journals, entered data, assisted with data analysis and manuscript preparation

Both authors read and approved the final manuscript.

\section{Acknowledgements}

We thank Elizabeth Hankinson from Wake Forest University for her help in reviewing articles. We thank Paula Gardiner for her constructive feedback on earlier versions of this manuscript. EH and PG received no financial compensation for contributing to this work. Support: Dr. Kemper is supported by NIH NCCAM Mid-Career Award K24-AT00022207. The contents of this manuscript are solely the responsibility of the authors and do not necessarily represents the official views of the NCCAM or the National Institutes of Health.

\section{References}

I. Eisenberg DM, Kessler RC, Foster C, Norlock FE, Calkins DR, Delbanco TL: Unconventional medicine in the United States. Prevalence, costs, and patterns of use. $N$ Engl J Med 1993 , 328:246-252.

2. Eisenberg DM, Davis RB, Ettner SL, Appel S, Wilkey S, Van Rompay $M$, Kessler RC: Trends in alternative medicine use in the United States, 1990-1997: results of a follow-up national survey. JAMA 1998, 280: I569-I575.

3. Barnes PM, Powell-Griner E, McFann K, Nahin RL: Complementary and alternative medicine use among adults: United States, 2002. Adv Data 2004: I-19.

4. Tindle HA, Davis RB, Phillips RS, Eisenberg DM: Trends in use of complementary and alternative medicine by US adults: 1 997-2002. Altern Ther Health Med 2005, I I:42-49.

5. Bell RA, Suerken CK, Grzywacz JG, Lang W, Quandt SA, Arcury TA Complementary and alternative medicine use among adults with diabetes in the United States. Altern Ther Health Med 2006 1 2:16-22.

6. Grzywacz JG, Suerken CK, Quandt SA, Bell RA, Lang W, Arcury TA Older adults' use of complementary and alternative medicine for mental health: findings from the 2002 Nationa
Health Interview Survey. I Altern Complement Med 2006, I 2:467-473.

7. Carlson MJ, Krahn G: Use of complementary and alternative medicine practitioners by people with physical disabilities: estimates from a National US Survey. Disabil Rehabil 2006, 28:505-5I3.

8. Saydah $\mathrm{SH}$, Eberhardt MS: Use of complementary and alternative medicine among adults with chronic diseases: United States 2002. J Altern Complement Med 2006, I 2:805-8I2.

9. Pearson NJ, Johnson LL, Nahin RL: Insomnia, trouble sleeping, and complementary and alternative medicine: Analysis of the $\mathbf{2 0 0 2}$ national health interview survey data. Arch Intern Med 2006, 166:1775-1782.

10. Kessler RC, Soukup J, Davis RB, Foster DF, Wilkey SA, Van Rompay $M M$, Eisenberg DM: The use of complementary and alternative therapies to treat anxiety and depression in the United States. Am J Psychiatry 200I, I 58:289-294.

II. Kennedy J: Herb and supplement use in the US adult population. Clin Ther 2005, 27:1847-1858.

12. Gardiner P, Graham R, Legedza AT, Ahn AC, Eisenberg DM, Phillips RS: Factors associated with herbal therapy use by adults in the United States. Altern Ther Health Med 2007, I 3:22-29.

13. Robbins JM, Cleves MA, Collins HB, Andrews N, Smith LN, Hobbs CA: Randomized trial of a physician-based intervention to increase the use of folic acid supplements among women. Am J Obstet Gynecol 2005, I 92: I I 26- I I 32.

14. Sibinga EM, Ottolini MC, Duggan AK, Wilson MH: Parent-pediatrician communication about complementary and alternative medicine use for children. Clin Pediatr (Phila) 2004, 43:367-373.

I5. Busse JW, Heaton G, Wu P, Wilson KR, Mills EJ: Disclosure of natural product use to primary care physicians: a cross-sectional survey of naturopathic clinic attendees. Mayo Clin Proc 2005, 80:616-623.

16. Bent S, Ko R: Commonly used herbal medicines in the United States: a review. Am J Med 2004, I I 6:478-485

17. Beal T, Kemper KJ, Gardiner P, Woods C: Long-term impact of four different strategies for delivering an on-line curriculum about herbs and other dietary supplements. BMC Med Educ 2006, 6:39.

18. Cohen MH, Hrbek A, Davis RB, Schachter SC, Kemper KJ, Boyer EW, Eisenberg DM: Emerging credentialing practices, malpractice liability policies, and guidelines governing complementary and alternative medical practices and dietary supplement recommendations: a descriptive study of 19 integrative health care centers in the United States. Arch Intern Med 2005 I 65:289-295.

19. Eisenberg DM: Advising patients who seek alternative medical therapies. Ann Intern Med 1997, I 27:61-69.

20. Gardiner P, Graham RE, Legedza AT, Eisenberg DM, Phillips RS: Factors associated with dietary supplement use among prescription medication users. Arch Intern Med 2006 , 166:1968-1974

21. Kemper KJ, Gardiner P, Gobble J, Woods C: Expertise about herbs and dietary supplements among diverse health professionals. BMC Complement Altern Med 2006, 6:15.

22. Manheimer E, Berman B: NCCAM support for the Cochrane Collaboration CAM Field. Complement Ther Med 2003, | I:268-27| |

23. Liu $Y$, Doucette WR, Farris KB, Nayakankuppam D: Drug information-seeking intention and behavior after exposure to directto-consumer advertisement of prescription drugs. Res Social Adm Pharm 2005, I:251-269.

24. Lyles A: Direct marketing of pharmaceuticals to consumers. Annu Rev Public Health 2002, 23:73-9I.

25. Smith R: Medical journals are an extension of the marketing arm of pharmaceutical companies. PLoS Med 2005, 2:el 38.

26. Lexchin ]: Interactions between physicians and the pharmaceutical industry: what does the literature say? CMAJ 1993 , | 49: | 40 | - 407

27. Epstein RA: Influence of pharmaceutical funding on the conclusions of meta-analyses. Bmj 2007, 335: I I 67.

28. Tsai AC: Conflicts between commercial and scientific interests in pharmaceutical advertising for medical journals. Int J Health Serv 2003, 33:751-768.

29. Brennan TA, Rothman DJ, Blank L, Blumenthal D, Chimonas SC, Cohen JJ, Goldman J, Kassirer JP, Kimball H, Naughton J, Smelser N: 
Health industry practices that create conflicts of interest: a policy proposal for academic medical centers. JAMA 2006, 295:429-433.

30. Coleman DL, Kazdin AE, Miller LA, Morrow JS, Udelsman R: Guidelines for interactions between clinical faculty and the pharmaceutical industry: one medical school's approach. Acad Med 2006, 8I:I54-160.

31. Lo B, Wolf LE, Berkeley A: Conflict-of-interest policies for investigators in clinical trials. N Engl J Med 2000, 343:|6|6-I620.

32. Kirch DG: Conflict-of-interest management: efforts and insights from the Association of American Medical Colleges. Cleve Clin J Med 2007, 74(Suppl 2):S23-25. discussion S32-27.

33. Jacobson MF, Sharpe VA, Angell M, Ashford NA, Blum A, Chary LK, Cho M, Coull BC, Davis D, Doolittle RF, et al.: Editorial policies on financial disclosure. Nat Neurosci 2003, 6: I00I.

34. Lexchin J, Light DW: Commercial influence and the content of medical journals. BMJ 2006, 332: |444-| 447.

35. McFadden DW, Calvario E, Graves $C$ : The devil is in the details: the pharmaceutical industry's use of gifts to physicians as marketing strategy. I Surg Res 2007, | 40: I-5

36. Wazana A: Physicians and the pharmaceutical industry: is a gift ever just a gift? JAMA 2000, 283:373-380.

37. Wilkes MS, Kravitz RL: Policies, practices, and attitudes of North American medical journal editors. J Gen Intern Med 1995, I 0:443-450.

38. Friedman L, Richter ED: Conflicts of interest and scientific integrity. Int J Occup Environ Health 2005, I I:205-206.

39. Buettner C, Phillips RS, Davis RB, Gardiner P, Mittleman MA: Use of dietary supplements among United States adults with coronary artery disease and atherosclerotic risks. Am J Cardiol 2007, 99:661-666.

40. NIH State-of-the-Science Conference Statement on Multivitamin/Mineral Supplements and Chronic Disease Prevention. NIH Consens State Sci Statements 2006, 23: I-30.

41. North American Menopause Society: The role of calcium in periand postmenopausal women 2006 position statement of the North American Menopause Society. Menopause 2006 , 13:862-877. quiz 878-880.

42. Sood A, Knudsen K, Sood R, Wahner-Roedler DL, Barnes SA, Bardia A, Bauer BA: Publication bias for CAM trials in the highest impact factor medicine journals is partly due to geographical bias. J Clin Epidemiol 2007, 60: I I23-1 I 26.

\section{Pre-publication history}

The pre-publication history for this paper can be accessed here:

http://www.biomedcentral.com/1472-6882/8/11/prepub

\section{Publish with Biomed Central and every scientist can read your work free of charge}

"BioMed Central will be the most significant development for disseminating the results of biomedical research in our lifetime. "

Sir Paul Nurse, Cancer Research UK

Your research papers will be:

- available free of charge to the entire biomedical community

- peer reviewed and published immediately upon acceptance

- cited in PubMed and archived on PubMed Central

- yours - you keep the copyright
BioMedcentral 